\title{
Cor e Infográfico: $O$ Design da Informação no livro didático
}

\author{
Color and Infographic: The Information Design in schoolbook
}

\author{
Milena Quattrer, Anna Paula Silva Gouveia
}

cor,

infográfico, livro didático color,

infographic, schoolbook
Este artigo é parte da pesquisa de Mestrado em Artes Visuais, que teve como objetivo compreender o quanto a relação entre a cor e os outros elementos do infográfico interfere no processo de transmissão da informação e como os infográficos, publicados em jornais e revistas, contribuem para o aprimoramento daqueles destinados aos livros didáticos. Objetiva-se, neste artigo, apresentar as reflexões geradas a partir de: iniciativas de projetos realizados com os alunos do Ensino Fundamental; análises de infográficos publicados em livros didáticos e daqueles publicados em jornais e revistas e premiados no Malofiej; entrevistas realizadas com professores do Ensino Fundamental e membro do júri do Malofiej. Tais reflexões forneceram apontamentos importantes sobre o que pode ser aproveitado dos infográficos premiados para o aprimoramento dos que são destinados aos livros didáticos, em especial no uso da cor, e demonstraram como é importante proporcionar situações de ensino-aprendizagem, nas quais o aluno tenha a oportunidade de se apropriar dos códigos visuais e, consequentemente, ampliar sua cultura visual.

This article is part of the Research Master in Visual Arts, which aimed to understand how the relationship between color and other elements of the infographics interfere with the process of information transmission, and how infographics published in newspapers and magazines can contribute to improve the ones used in Schoolbooks. The ideas presented in this article were generated from: two project initiatives undertaken with elementary school students; analysis of the infographics published in schoolbooks and those published in newspapers and magazines and awarded at Malofiej; interviews with elementary school teachers and a member of the jury of Malofiej. Such reflections provide important notes about what can be availed from the awarded infographics in order to improve the infographics made for the schoolbooks, especially in regards of the use of color, and demonstrated how important it is to provide teaching-learning situations in which the students have the opportunity to appropriate the visual codes hence their visual culture. 


\section{Introdução}

A cor é uma valiosa ferramenta para a comunicação visual, por seu potencial em contribuir na organização e hierarquização dos dados. E, como já demonstrado em pesquisas anteriores ${ }^{1}$, a cor pode atribuir, ou a ela podem ser atribuídos, sentidos e valores de acordo com o contexto em que é aplicada ou com o acorde cromático em que está inserida. O infográfico ${ }^{2}$, por sua vez, é um importante instrumento capaz de tornar a informação interessante, dinâmica e atrativa, permitindo que a ideia principal do que está sendo transmitido seja captada em poucos minutos. A dissertação de Mestrado, da qual este artigo é fruto, se preocupa em discutir e analisar como a cor estrutura e otimiza a transmissão da informação nos infográficos, publicados em livros didáticos. Desse modo, optei por selecionar infográficos publicados em livros didáticos adotados através do 'Programa Nacional do Livro Didático's, nas disciplinas de Geografia, História e Ciências, e compará-los aos infográficos publicados em mídia impressa e premiados nas edições 18, 19 e 20 dos 'Premios Internacionales Malofiej de Infografía”, com o objetivo de compreender o quanto a relação entre a cor e os outros elementos do infográfico pode interferir no processo de transmissão da informação e, também, como os infográficos premiados podem contribuir para o aprimoramento dos infográficos destinados aos livros didáticos, dando, assim, continuidade às discussões suscitadas pela pesquisa de Iniciação Científica.

\section{Procedimentos metodológicos}

Para alcançar os objetivos propostos, foram realizados o levantamento dos infográficos impressos, premiados nas edições 18, 19 e 20 dos 'Premios Internacionales Malofiej de Infografía', bem como dos infográficos impressos publicados nos livros didáticos adotados, através do Programa Nacional do Livro Didático (PNLD) - 2011, pelos professores responsáveis pelas disciplinas de Ciências, Geografia e História do ciclo IV5 do Ensino Fundamental da EMEF CAIC ‘Prof

\footnotetext{
1 "O uso das cores em infográficos de divulgação científica", 2010. Iniciação Científica realizada sob orientação da Profa Dra Anna Paula Silva Gouveia, no Departamento de Artes Plásticas do Instituto de Artes - Unicamp e apoiada pelo Programa Institucional de Bolsas de Iniciação Científica (PIBIC - Unicamp)

2 Para a pesquisa, da qual este artigo é fruto, 'infográfico' se refere única e exclusivamente à representação esquemática da informação através da integração entre elementos gráfico-visuais - ilustrações, fotografias, gráficos, tabelas, cronologias, fluxogramas, organogramas, mapas, diagramas - e textos que devem ser, sobretudo, sintéticos. 3 O 'Programa Nacional do Livro Didático' (PNLD) é um programa do governo federal brasileiro de distribuição de livros didáticos aos alunos de educação básica da rede pública. 4 Os 'Premios Internacionales Malofiej de Infografía' - mais conhecidos como Malofiej - são promovidos anualmente em Pamplona, na Espanha, pela 'Society for News Design' (SND-E). $5 \mathrm{O}$ ciclo IV corresponde aos $8^{\circ}$ e $9^{\circ}$ anos do Ensino Fundamental.
} 
Zeferino Vaz', localizada no município de Campinas/SP. A partir desse levantamento, os infográficos foram selecionados e agrupados para análises, de acordo com a proximidade no assunto, forma de abordagem e, principalmente, no uso da cor.

É importante salientar que a cor é o elemento de destaque nas comparações e análises realizadas, por seu potencial de contribuir na organização e hierarquização dos dados, auxiliando na transmissão da informação e incorporando significados a ela. Para tanto, buscou-se em Edward R. Tufte (2011a) e Luciano Guimarães (2004) respaldo teórico para se discutir cor e informação.

Segundo Tufte, no design da informação, a cor é fundamentalmente aplicada para “(...) rotular ou legendar (cor como um substantivo), medir (cor como quantidade), representar ou imitar a realidade (cor como representação) e para animar ou decorar (cor como beleza)." (Tufte, 2011a:81) ${ }^{7}$

Sobre o conceito de cor-informação de Luciano Guimarães (2003):

(...) Considera-se a cor como informação todas as vezes em que sua aplicação desempenhar uma dessas funções responsáveis por organizar e hierarquizar informações ou lhes atribuir significado, seja sua atuação individual e autônoma ou integrada e dependente de outros elementos do texto visual em que foi aplicada (formas, figuras, texturas, textos, ou até mesmo sons e movimentos, como em produtos multimídia). (Guimarães, 2003:31).

A partir das afirmações de Tufte e Guimarães, optou-se por selecionar, comparar e analisar os infográficos em que a cor esteja aplicada para: (i) "rotular/legendar", ou seja, diferenciar um item de outro; e (ii) "medir", ou seja, indicar quantidade, profundidade etc. A escolha se deve ao fato de que, durante o levantamento nos livros didáticos adotados, verificou-se que "rotular/legendar" e "medir" eram pontos importantes nos infográficos aplicados no processo de ensino-aprendizagem, e as entrevistas com os professores confirmam isso.

A seguir, estão apresentados os infográficos selecionados para comparação e análises, organizados em pares, a partir da proximidade no assunto, forma de abordagem e aplicação da cor.

6 Optou-se pela EMEF CAIC 'Prof Zeferino Vaz', pelo fato da pesquisadora ser docente efetiva do quadro de funcionários dessa unidade escolar e, principalmente, por desenvolver, desde o ano letivo de 2011, o projeto 'Infografia - o Design da Informação na imprensa e no ambiente escolar' com alunos regularmente matriculados nos ciclos III e IV nessa unidade escolar. 7 Tradução livre. 


\subsection{Infográficos selecionados para análise ${ }^{8}$}

\subsubsection{Geografia}

1. Os infográficos agrupados no Quadro 1 abordam o assunto 'distribuição da água nos continentes' através do elemento gráfico-visual 'mapa' e aplicam a cor essencialmente para indicar quantidade, ou seja, 'medir' e diferenciar um item de outro, 'rotular/legendar'.

Quadro 1 Infográficos analisados no Grupo 1 - Geografia

\begin{tabular}{l|llll}
\hline Título do infográgico & Autor & Publicação & $\begin{array}{l}\text { Elemento } \\
\text { gráfico-visual } \\
\text { principal }\end{array}$ & $\begin{array}{l}\text { Aplicação da } \\
\text { cor }\end{array}$ \\
\hline $\begin{array}{l}\text { Recursos hídricos renováveis internos, por pessoa, } \\
\text { por ano (2005) e projeção para 2050 - em } \\
\text { metros cúbicos (Figura 1) }\end{array}$ & $\begin{array}{l}\text { Anderson de } \\
\text { Andrade Pimentel }\end{array}$ & $\begin{array}{l}\text { Projeto } \\
\text { Araribá: } \\
\text { Geografia - } \\
\text { Volume 4 }\end{array}$ & Mapa & Medir \\
\hline World of rivers9 (Figura 2) & $\begin{array}{llll}\text { Elaine Bradley, } \\
\text { Jane Vassels, } \\
\text { Christy Ullich, } \\
\text { Kaitlin Yarnall, } \\
\text { Debbie Gibbons e } \\
\text { Dianne Hunt. }\end{array}$ & $\begin{array}{l}\text { Geographic } \\
\text { Magazine } \\
\text { (EUA) }\end{array}$ & & Mapa \\
& & & \\
\end{tabular}

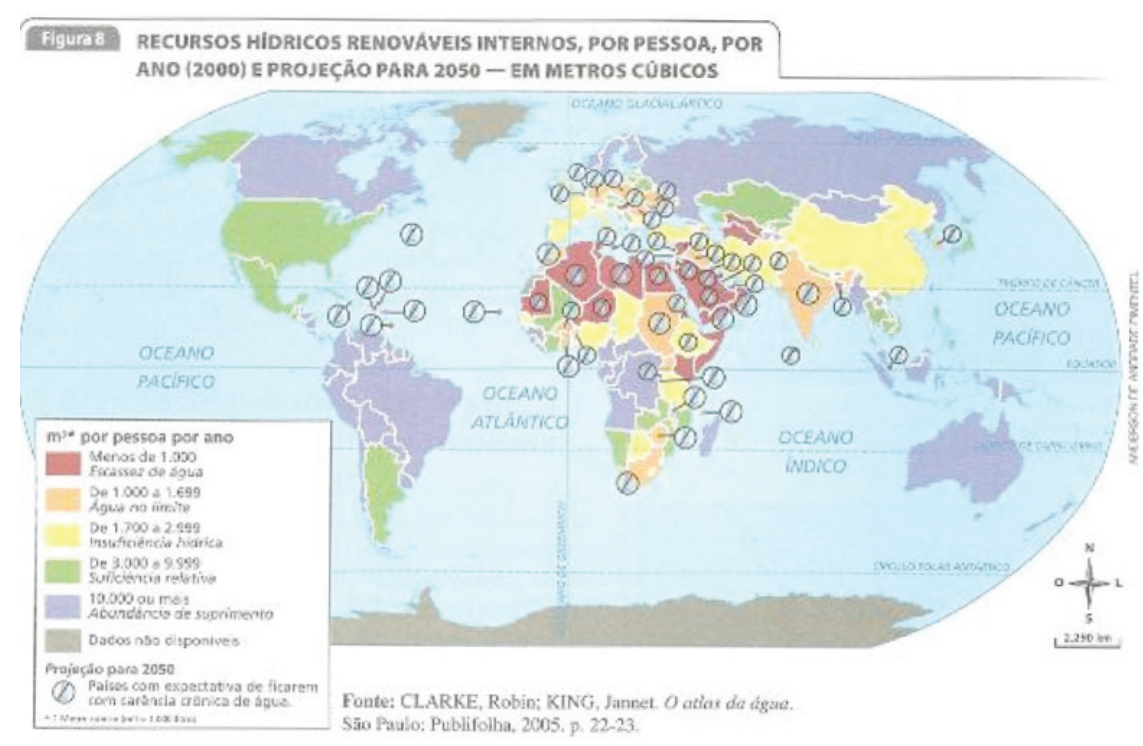

Figura 1 Infográfico 'Recursos hídricos renováveis internos, por pessoa, por ano (2005) e projeção para 2050 - em metros cúbicos'.

8 De acordo com a Lei $n^{\circ}$ 9.610/98, Art. 46, inciso III, as reproduções dos infográficos analisados, apresentadas neste artigo para fins de estudo e crítica, não constituem ofensa aos direitos autorais.

9 Ouro na categoria Reportagem e eleito o vencedor da categoria ‘Best map/ Miguel Urabayen' do Malofiej 19. 


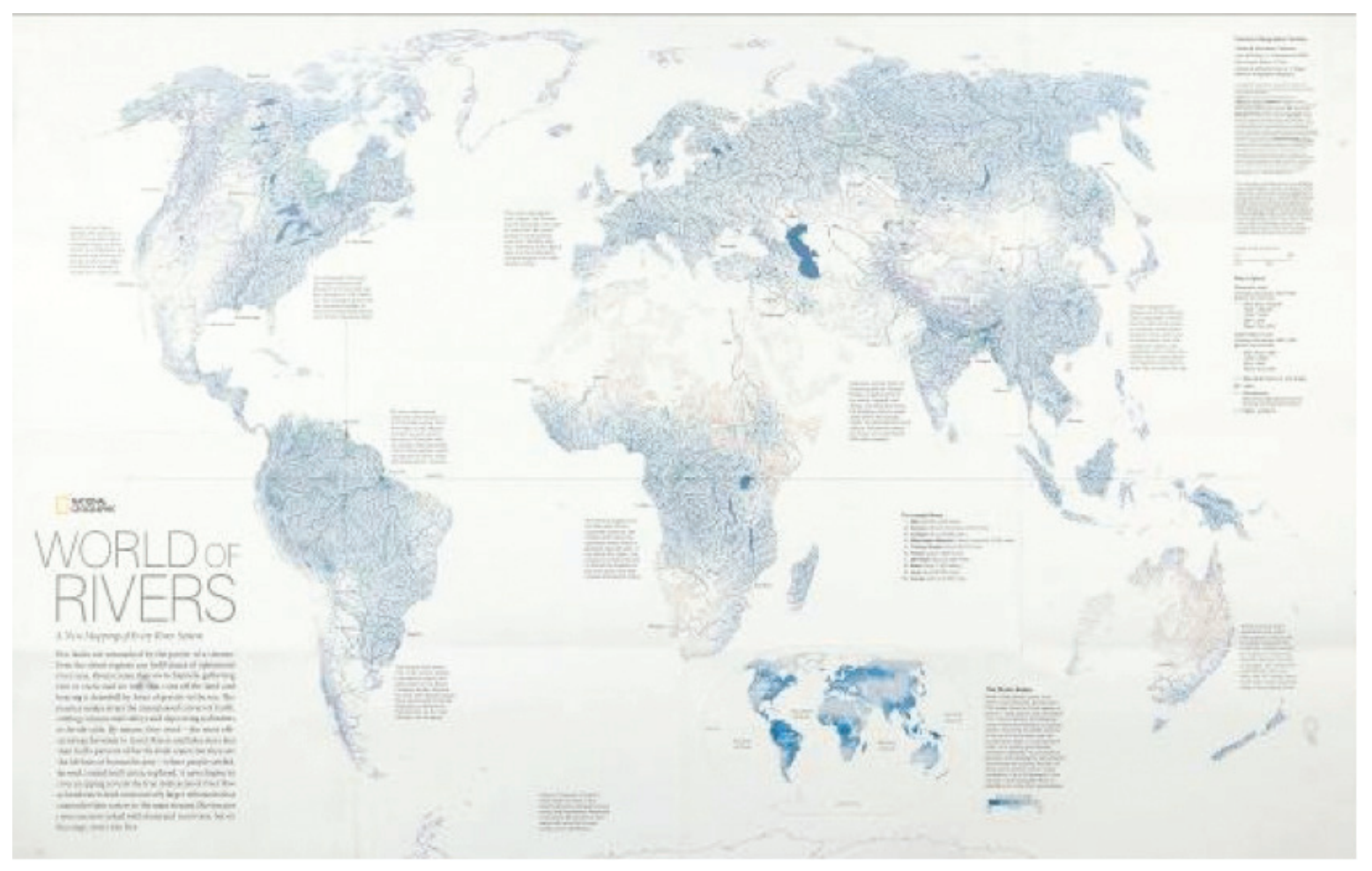

Figura 2 'World of rivers'.

2. Estão relacionados no Quadro 2 os infográficos que apresentam em comum o assunto 'fome na África', os elementos gráficovisuais 'mapa' e 'gráfico' e aplicam a cor para 'rotular/legendar' e 'medir'.

Quadro 2 Infográficos analisados no Grupo 2 - Geografia.

\begin{tabular}{|c|c|c|c|c|}
\hline Título do infográfico & Autor & Publicação & $\begin{array}{l}\text { Elemento } \\
\text { gráfico-visual } \\
\text { principal }\end{array}$ & $\begin{array}{l}\text { Aplicação da } \\
\text { cor }\end{array}$ \\
\hline $\begin{array}{l}\text { Fome e doenças: subprodutos da pobreza } \\
\text { (Figura 3) }\end{array}$ & $\begin{array}{l}\text { Alessandro Passos } \\
\text { da Costa }\end{array}$ & $\begin{array}{l}\text { Projeto } \\
\text { Araribá: } \\
\text { Geografia - } \\
\text { Volume } 4\end{array}$ & $\begin{array}{l}\text { Mapa e } \\
\text { gráfico }\end{array}$ & $\begin{array}{l}\text { Rotular/ } \\
\text { legendar e } \\
\text { medir }\end{array}$ \\
\hline $\begin{array}{l}\text { Fome no corno da África é uma tempestade } \\
\text { perfeita em termos de crise humanitária }{ }^{10} \\
\text { (Figura 4) }\end{array}$ & $\begin{array}{l}\text { Joaquim Guerreiro, } \\
\text { Cátia Mendonça, } \\
\text { Célia Rodrigues e } \\
\text { José Alves. }\end{array}$ & $\begin{array}{l}\text { Público } \\
\text { (Portugal) }\end{array}$ & $\begin{array}{l}\text { Mapa, } \\
\text { cronologia, } \\
\text { diagrama e } \\
\text { gráfico }\end{array}$ & $\begin{array}{l}\text { Rotular/ } \\
\text { legendar e } \\
\text { medir }\end{array}$ \\
\hline
\end{tabular}

10 Prata na categoria Portfólio do Malofiej 20. 


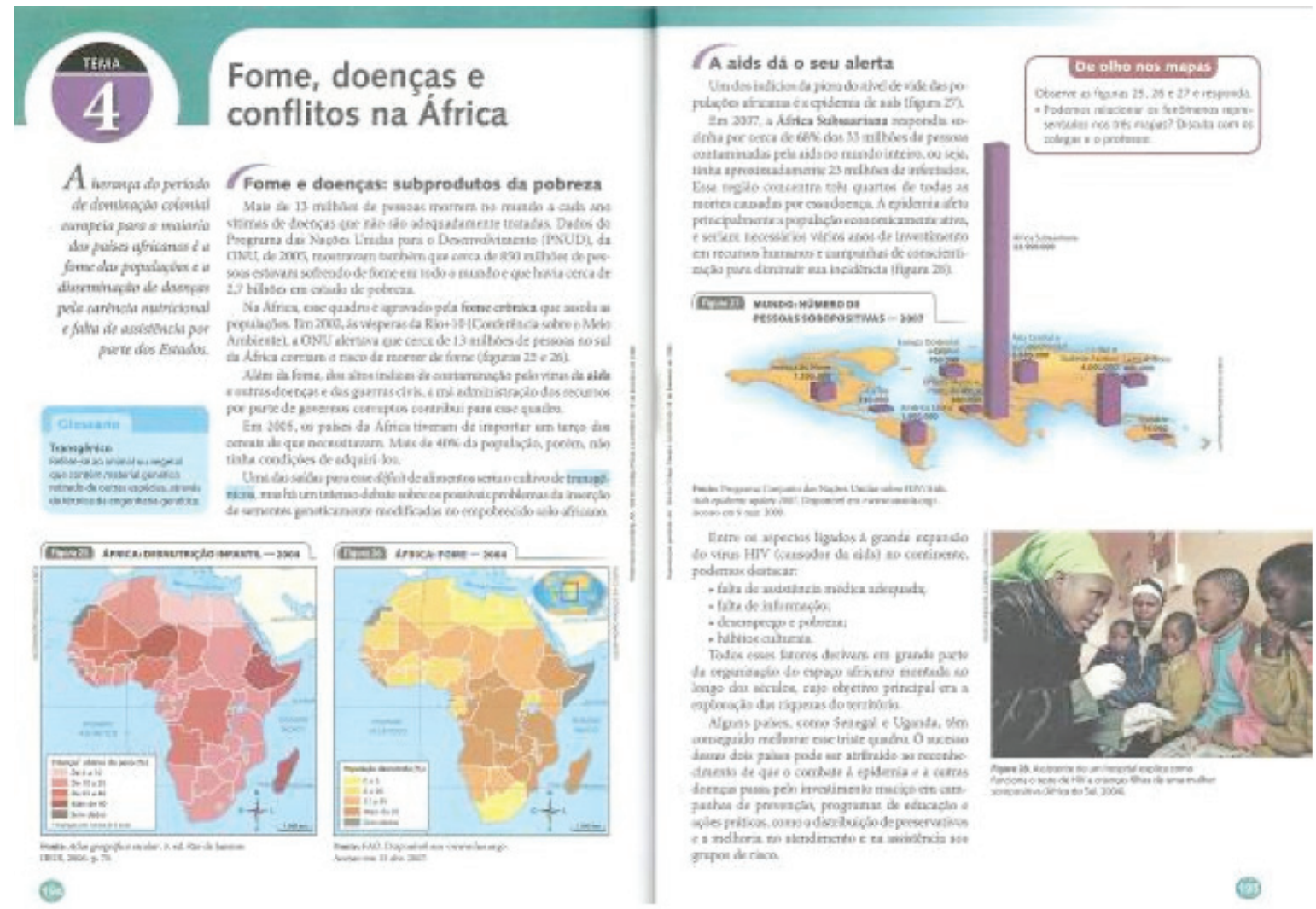

Figura 3 Páginas com o infográfico 'Fome e doenças: subprodutos da pobreza'.

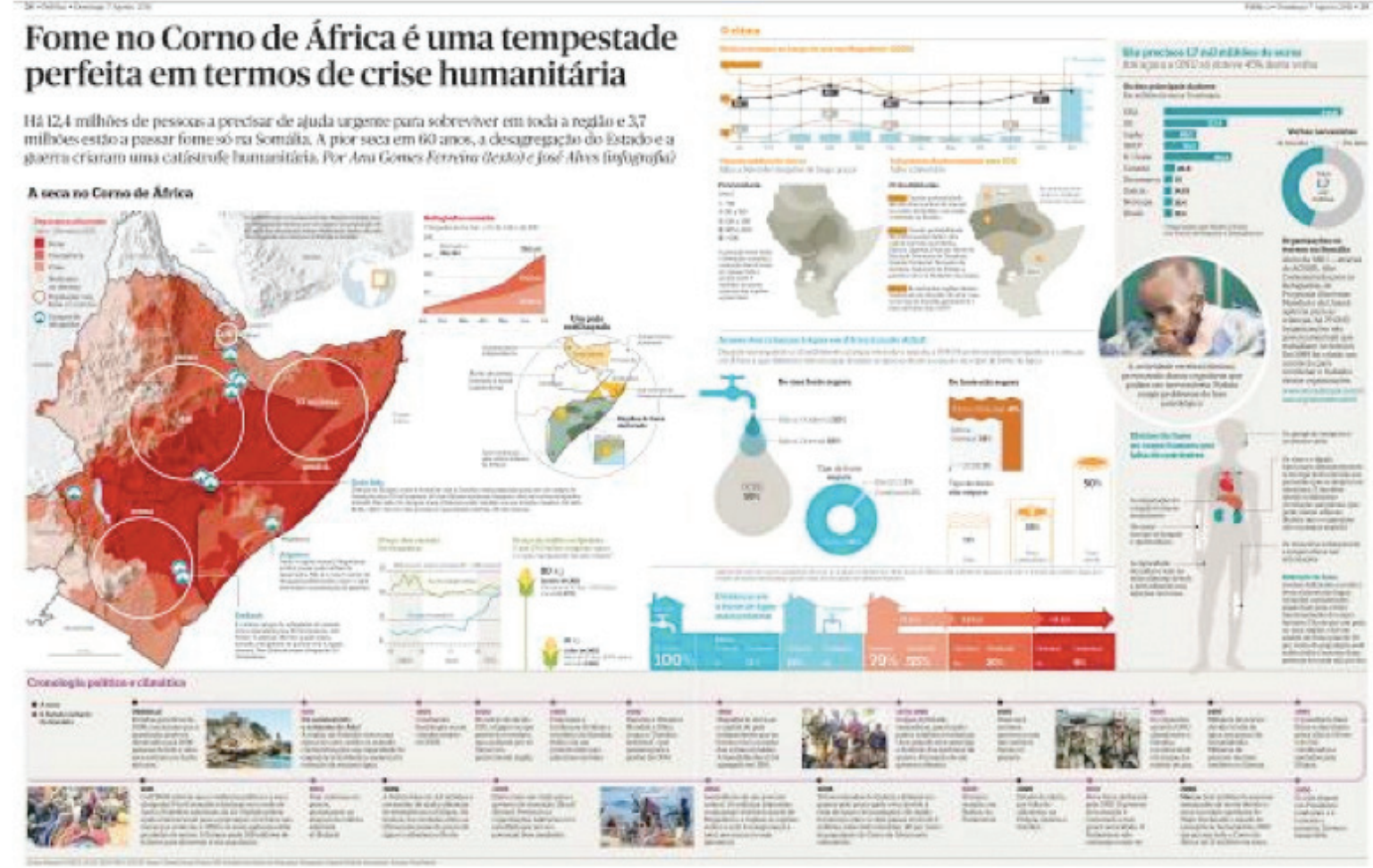

Figura 4 'Fome no corno da África é uma tempestade perfeita em termos de crise humanitária. 


\subsubsection{História}

No Quadro 3 estão agrupados os infográficos que têm em comum a apresentação de dados estatísticos sobre o Brasil, essencialmente, através do elemento gráfico-visual 'mapa' e aplicam a cor para 'medir'.

Quadro 3 Infográficos analisados no Grupo de História.

\begin{tabular}{|c|c|c|c|c|}
\hline Título do Infográfico & Autor & Publicação & $\begin{array}{l}\text { Elemento } \\
\text { gráfico-visual } \\
\text { principal }\end{array}$ & $\begin{array}{l}\text { Aplicação da } \\
\text { cor }\end{array}$ \\
\hline $\begin{array}{l}\text { Inclusão social no Brasil de acordo com o IDH } \\
\text { (Figura 5) }\end{array}$ & Não consta & $\begin{array}{l}\text { História em } \\
\text { Projetos - } \\
\text { Volume } 4\end{array}$ & Mapa & Medir \\
\hline Geografia do Voto ${ }^{11}$ (Figura 6) & $\begin{array}{l}\text { Fabio Sales, } \\
\text { Gabriela Allegro, } \\
\text { Regina Elisabeth, } \\
\text { Glauco Lara, } \\
\text { Eduardo Asta, } \\
\text { Rubens Paiva, } \\
\text { Rodrigo Fortes, } \\
\text { Gisela Oliveira e } \\
\text { Carlos Lemos }\end{array}$ & $\begin{array}{l}\text { O Estado de S. } \\
\text { Paulo (Brasil) }\end{array}$ & $\begin{array}{l}\text { Mapa, tabela } \\
\text { e gráfico }\end{array}$ & $\begin{array}{l}\text { Medir e } \\
\text { Rotular/ } \\
\text { legendar }\end{array}$ \\
\hline
\end{tabular}

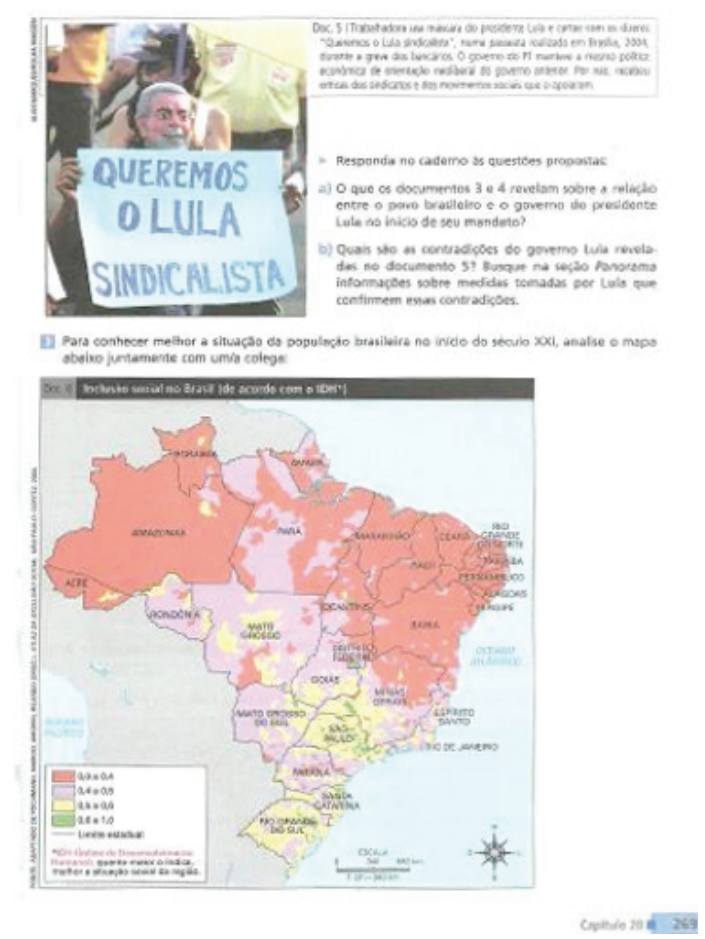

Figura 5 Página com o infográfico ‘Inclusão social no Brasil de acordo com o IDH'.

11 Bronze na categoria Reportagem Bronze do Malofiej 19. 


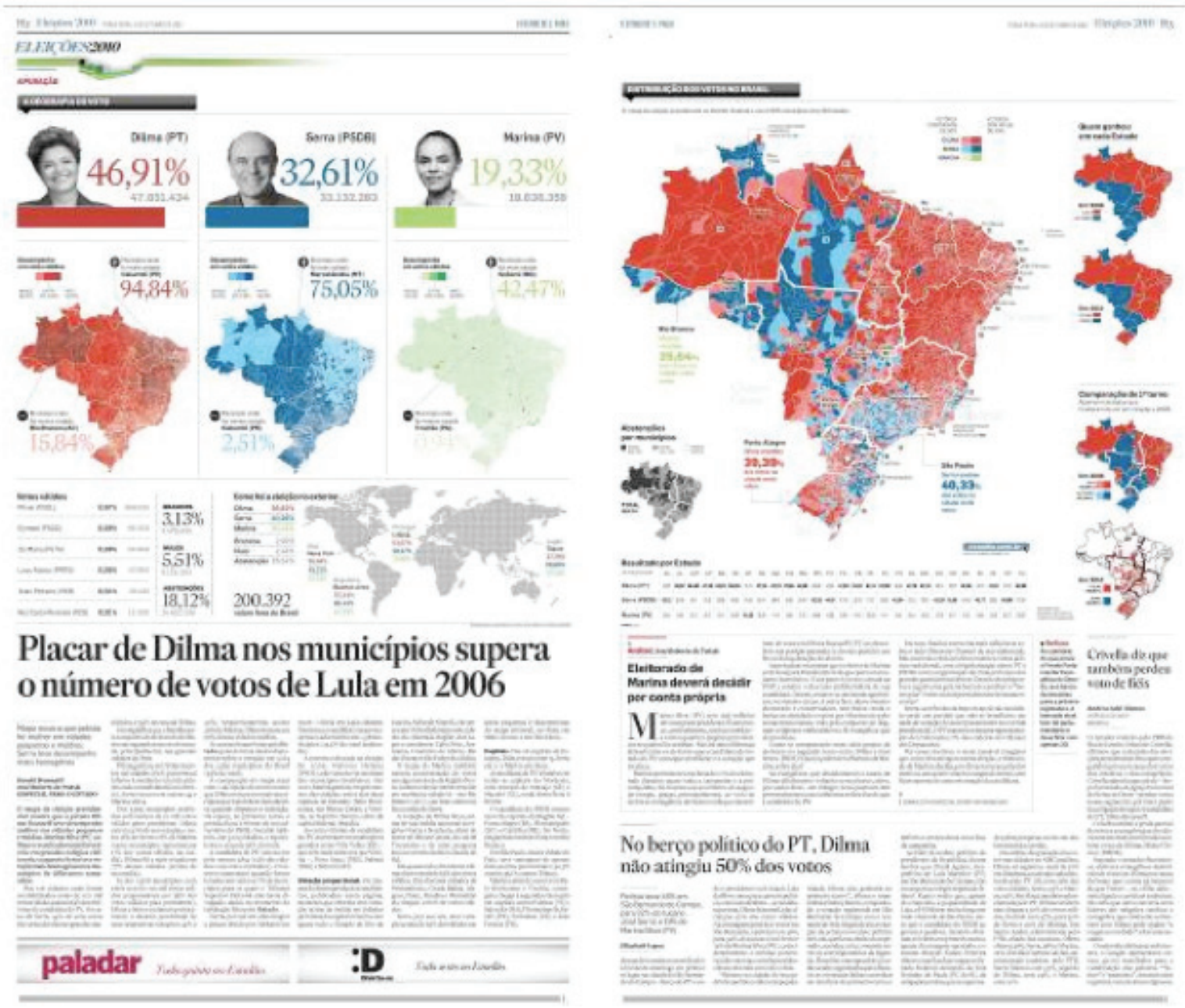

Figura 6 Paginas com o infográfico 'Geografia do voto’.

\subsubsection{Ciências}

1. O Quadro 4 é formado por infográficos que apresentam o funcionamento do cérebro, através do elemento gráfico-visual 'diagrama' e aplicam a cor para diferenciar um item de outro, ou seja, 'rotular/legendar'.

Quadro 4 Infográficos analisados no Grupo 1 - Ciências.

\begin{tabular}{|c|c|c|c|c|}
\hline Título do Infográfico & Autor & Publicação & $\begin{array}{l}\text { Elemento } \\
\text { gráfico-visual } \\
\text { principal }\end{array}$ & $\begin{array}{l}\text { Aplicação da } \\
\text { cor }\end{array}$ \\
\hline $\begin{array}{l}\text { Esquema da atuação de algumas partes do } \\
\text { encéfalo humano (Figura 7) }\end{array}$ & Paulo Manzi & $\begin{array}{l}\text { Ciências } \\
\text { Naturais - } \\
\text { Aprendendo } \\
\text { com o } \\
\text { Cotidiano - } \\
\text { Volume } 3\end{array}$ & Diagrama & $\begin{array}{l}\text { Rotular/ } \\
\text { legendar }\end{array}$ \\
\hline
\end{tabular}


Quadro 4 Infográficos analisados no Grupo 1 - Ciências.

\begin{tabular}{|c|c|c|c|c|}
\hline Título do Infográfico & Autor & Publicação & $\begin{array}{l}\text { Elemento } \\
\text { gráfico-visual } \\
\text { principal }\end{array}$ & $\begin{array}{l}\text { Aplicação da } \\
\text { cor }\end{array}$ \\
\hline The brain in slumber ${ }^{12}$ (Figura 8) & $\begin{array}{l}\text { Juan Velasco e } \\
\text { equipe }\end{array}$ & $\begin{array}{l}\text { National } \\
\text { Geographic } \\
\text { Magazine } \\
\text { (EUA) }\end{array}$ & $\begin{array}{l}\text { Diagrama e } \\
\text { gráfico }\end{array}$ & $\begin{array}{l}\text { Rotular/ } \\
\text { legendar e } \\
\text { medir }\end{array}$ \\
\hline
\end{tabular}

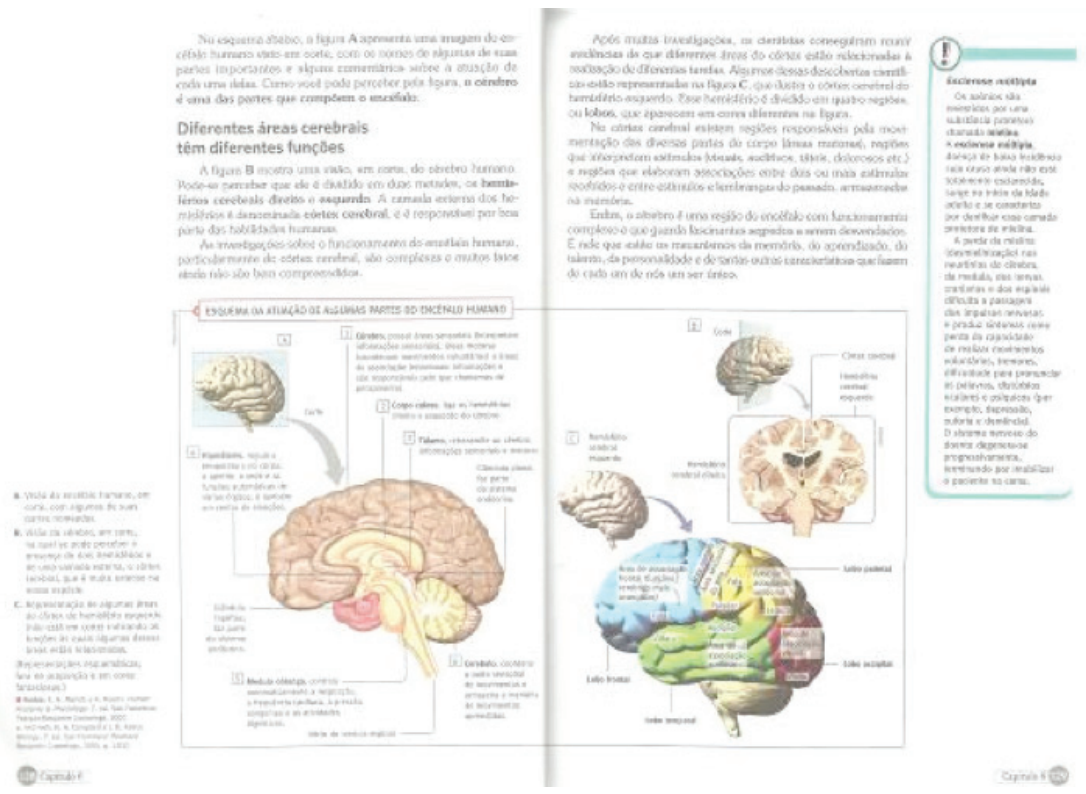

Figura 7 Páginas com o infográfico 'Esquema da atuação de algumas partes do encéfalo humano'.

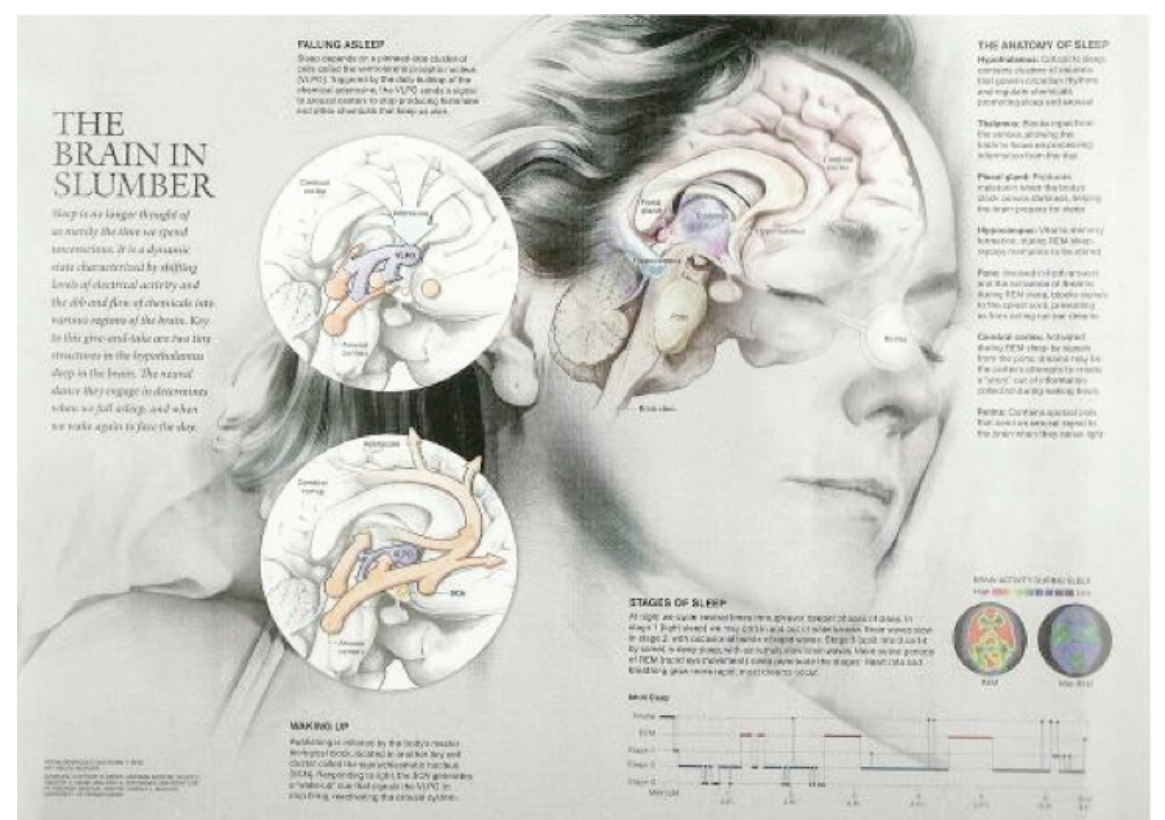

Figura 8 'The brain in slumber'.

12 Prata na categoria Portfólio do Malofiej 19

Infodesıgn | São Paulo | v. 10 | n. 3 [2013], p. 323 - 341 
2. Por fim, no Quadro 5 estão agrupados os infográficos que apresentam sistema reprodutor masculino e feminino, através do elemento gráfico-visual 'diagrama' e aplicam a cor para 'rotular/legendar'.

Quadro 5 Infográficos analisados no Grupo 2- Ciências.

\begin{tabular}{|c|c|c|c|c|}
\hline Título do Infográfico & Autor & Publicação & $\begin{array}{l}\text { Elemento } \\
\text { gráfico-visual } \\
\text { principal }\end{array}$ & $\begin{array}{l}\text { Aplicação da } \\
\text { cor }\end{array}$ \\
\hline $\begin{array}{l}\text { O sistema genital masculino' e 'O sistema genital } \\
\text { feminino (Figura 9) }\end{array}$ & Cecília Iwashita & $\begin{array}{l}\text { Ciências } \\
\text { Naturais - } \\
\text { Aprendendo } \\
\text { com o } \\
\text { Cotidiano - } \\
\text { Volume } 4\end{array}$ & Diagrama & $\begin{array}{l}\text { Rotular/ } \\
\text { legendar }\end{array}$ \\
\hline As idades do $\operatorname{sexo}^{13}$ (Figura 10) & Sofia Miguel Rosa & $\begin{array}{l}\text { Expresso } \\
\text { (Portugal) }\end{array}$ & Diagrama & $\begin{array}{l}\text { Rotular/ } \\
\text { legendar }\end{array}$ \\
\hline
\end{tabular}
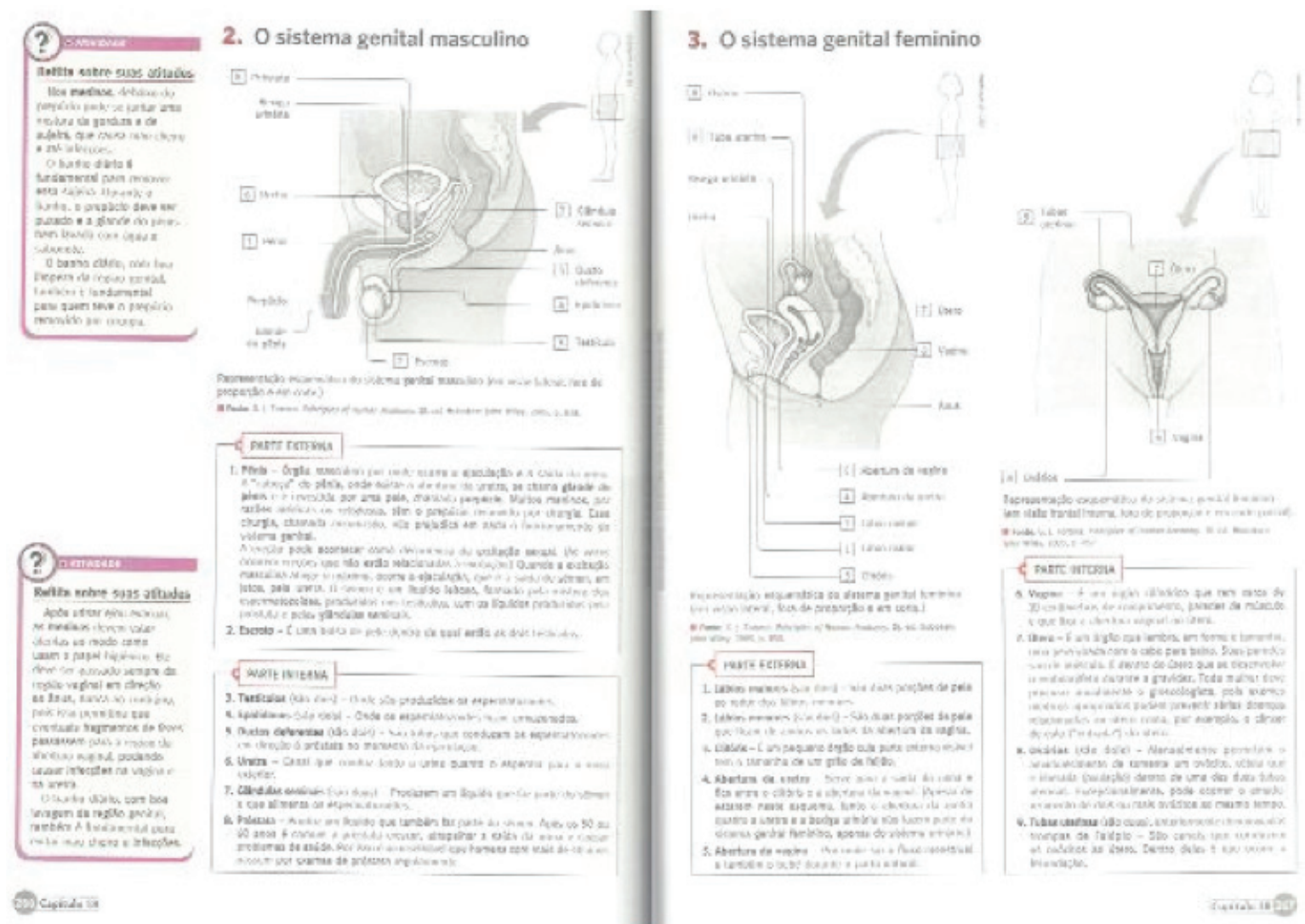

Figura 9 'O sistema genital masculino' e ‘O sistema genital feminino’.

13 Prata na categoria Reportagem do Malofiej 18. 


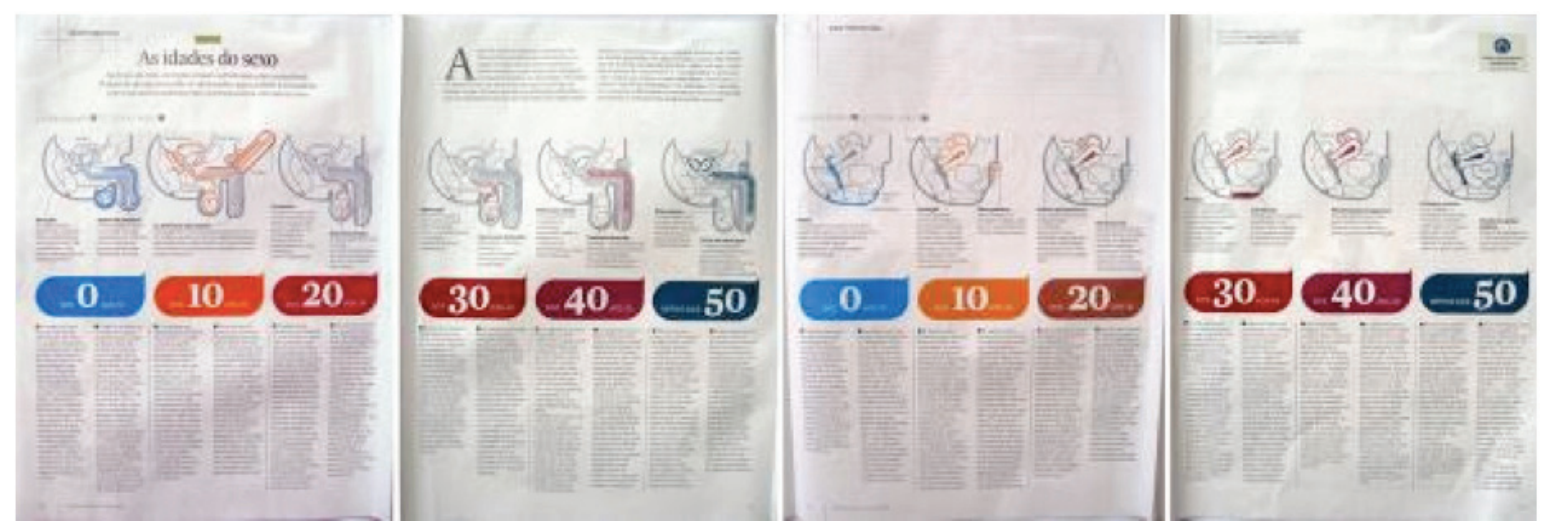

Figura 10 'As idades do sexo'.

\subsection{Parâmetros para análise da estrutura cromática dos infográficos selecionados}

Para a análise da estrutura cromática dos infográficos selecionados, os parâmetros de definição da cor 'matiz', 'luminosidade' e 'saturação' foram adotados. Segundo Guimarães,

Os três parâmetros para definição das cores são praticamente universais. Um primeiro para determinar a exata posição da cor no espectro eletromagnético; um segundo para determinar as atenuações ascendentes (clareamento) e descendentes (escurecimento) da cor; e um terceiro para determinar a proximidade da cor espectral com a sua correspondente em uma escala de tons de cinza. (2004:54-55)

Sendo assim, para a presente pesquisa, 'matiz' corresponde à posição da cor no espectro eletromagnético, 'luminosidade' se refere à variação de clareamento e escurecimento da cor, e 'saturação' à variação da cor em uma escala que parte da sua cor espectral (matiz) ao seu tom de cinza correspondente.

\subsection{Entrevistas}

Para este trabalho, optou-se pelo método de entrevista estruturada através de dois tipos de questionários: aberto e semiaberto. O questionário aberto foi aplicado na entrevista com a ex-editora de arte da revista Superinteressante e membro do júri da $16^{\underline{a}}$ edição do Malofiej, Renata Steffen, a fim de possibilitar o entendimento das particularidades do processo de elaboração do infográfico no ambiente da imprensa e, também, da estrutura e organização do Malofiej. O questionário semiaberto foi aplicado nas entrevistas com os professores do ensino fundamental da Rede Municipal de Campinas, com o intuito de verificar e compreender de que modo os infográficos publicados em livros didáticos participam e contribuem no processo de ensino-aprendizagem - em especial a cor-informação - e como as 
soluções propostas pelos infográficos premiados no Malofiej podem colaborar nesse processo.

Professores entrevistados: Eliane Maria Rodrigues Quinalha, Geografia; Murillo Scaranari Antunes, Geografia; Célia Garcia, História; Teresinha Cristina Bianco, História; e Frederico T. Magalhães, Ciências. Os professores foram entrevistados individualmente nas dependências da EMEF CAIC 'Professor Zeferino Vaz' em agosto de 2013. Durante as entrevistas, os professores tiveram em mãos o livro didático de sua disciplina, no qual o infográfico selecionado havia sido publicado, bem como a reprodução fotográfica do infográfico selecionado, premiado no Malofiej.

\section{Reflexões geradas a partir das análises dos infográficos e das entrevistas}

As análises dos infográficos e das entrevistas com os professores possibilitaram o levantamento de pontos importantes sobre o que pode ser aproveitado dos infográficos premiados no Malofiej para o aprimoramento dos infográficos destinados aos livros didáticos. São eles: (i) problemas e soluções de aplicação da cor; (ii) tamanho e disposição na página; (iii) combinação entre elementos gráfico-visuais.

\subsection{Problemas e soluções de aplicação da cor}

No primeiro ponto, destacam-se problemas e soluções de aplicação da cor, apresentados nos infográficos publicados em livros didáticos e nos infográficos premiados no Malofiej. As análises demonstraram que as escalas de valores e matizes podem ser grandes aliadas na transmissão da informação, em infográficos que apresentam dados numéricos, ao indicar quantidade ou profundidade (medir), bem como naqueles que demonstram o funcionamento de partes do corpo humano ao diferenciar um item de outro (rotular/legendar). Todavia, de acordo com o acorde cromático aplicado ou as variações de luminosidade e saturação nas escalas, o que antes era um aliado pode se tornar um vilão: escalas de matizes podem transformar infográficos em enigmas visuais $^{14}$ e comprometer o entendimento da informação. É o caso da escala de matizes aplicada em 'Inclusão social no Brasil de acordo com o IDH' (Figura 5). Para a professora Garcia, as cores poderiam ser mais contrastantes, de modo a facilitar a compreensão dos dados nas áreas em que predominam o violeta luminoso e o amarelo. Já na opinião da professora Bianco, substituir o violeta-luminoso por outra cor mais saturada ou, nas palavras da professora, "chocante", poderia comprometer a informação e prejudicar o contraste entre o vermelho

14 Tufte, 2011b:153. 
e o verde, que representam dois extremos importantes para o estudo do IDH.

Porque a ideia é direcionar o seu olhar justamente para o vermelho e depois você comparar com o verde. (...) as áreas onde tem mais problema com o IDH é o vermelho que te chama mais a atenção, contrastando com o verde, onde o IDH é mais elevado, mas são pequenas as áreas. Então, eu também preciso de uma cor que me chame, que me leve para lá, para eu perceber. E o suave, a suavidade das outras cores para mostrar onde a coisa é mais ou menos. (Teresinha Cristina Bianco)

Em todo caso, apesar do contraste entre os extremos dos dados representados em vermelho e verde se mostrar adequado, a legibilidade fica comprometida nas áreas onde são aplicados o violeta luminoso e o amarelo. O que já não ocorre no acorde cromático utilizado no infográfico premiado 'Geografia do voto' (Figura 6). De acordo com as análises, o contraste principal entre as escalas de luminosidade e saturação do vermelho e azul aplicado no infográfico antecipa o assunto (imediatamente o leitor é informado sobre o tema abordado: eleições), e contribui na hierarquia visual e organização das informações apresentadas (distribuição e porcentagem de votos de cada candidato). Segundo Guimarães (2004:110), "a utilização da informação cromática pela cultura pode determinar sistemas de agrupamento, identificação, armazenamento e transmissão diferentes".

A ação positiva da cor de antecipar o assunto e o enfoque dado pelo infográfico ocorre, também, nos casos em que o vermelho é aplicado em áreas que representam dados alarmantes, como em 'Recursos hídricos renováveis internos, por pessoa, por ano (2005) e projeção para 2050 - em metros cúbicos' (Figura 1) e no premiado 'Fome no corno da África é uma tempestade perfeita em termos de crise humanitária' (Figura 4). Nesses casos, o vermelho atrai a atenção do leitor para áreas problemáticas, assim como o laranja luminoso e pouco saturado, aplicado para representar os rios intermitentes no premiado 'World of rivers' (Figura 2) que, em contraste com o azul ciano e o branco, destaca as áreas com escassez de água. Sobre 'World of rivers', é possível afirmar ainda que o azul ciano aplicado em linhas e formas, que representam no mapa, respectivamente, rios e lagos, exerce a ação positiva de antecipação ${ }^{15}$, pois nesse contexto, imediatamente, o leitor associa azul ciano à agua. A relação entre cor e significado não é arbitrária ou acidental, ao contrário, é parte de um contexto cultural que, segundo Heller (2004), pode ser compreendido a partir da tradição histórica e do simbolismo psicológico. Nas convenções cartográficas, o azul e suas variações de luminosidade estão tradicionalmente ligados à representação da água. No entanto, os autores de 'World of rivers', 'Fome no corno da África é uma

15 Guimarães, 2003:91. 
tempestade perfeita em termos de crise humanitária' e 'Geografia do voto’ optam por aplicar o branco nas áreas que representam os mares e oceanos, o que, segundo as análises, não compromete o entendimento da informação e possibilita o uso dessas áreas para acrescentar outras informações importantes sobre o assunto abordado pelos infográficos.

Outra solução, apontada em um dos infográficos premiados e valorizada pelos professores entrevistados, foi o aumento da espessura da linha branca de divisão dos Estados, para delimitar as regiões do Brasil nos mapas apresentados em 'Geografia do voto' (Figura 6). A aplicação do branco nas linhas que indicam as divisões políticas entre Estados e países, entre outras coisas, contribui para evitar as imprecisões de leitura provocadas pelo contraste simultâneo entre os matizes. Esse recurso é também aplicado no infográfico 'Recursos hídricos renováveis internos, por pessoa, por ano (2005) e projeção para 2050 - em metros cúbicos' (Figura 1) e nos mapas de 'Fome, doenças e conflitos na África' (Figura 3).

Nos casos de representação do corpo humano, os infográficos premiados apontaram soluções funcionais, mas também exemplificaram alguns problemas importantes e que devem ser levados em conta no processo de construção do infográfico. No premiado 'As idades do sexo' (Figura 10), a aplicação do cinza nos diagramas (com constância de desenho ${ }^{16}$ ) associada aos detalhes coloridos (a partir de uma escala de matiz) contribuiu para identificar as estruturas e relacioná-las aos textos aos quais se referem. De acordo com as análises, acordes cromáticos de caráter artificial ao corpo humano contribuem para o entendimento da informação, ao serem aplicados para destacar os elementos importantes em diagramas anatômicos, como os apresentados em 'As idades do sexo' e 'Esquema da atuação de algumas partes do encéfalo humano' (Figura 7), este último publicado em livro didático. Todavia, segundo a pesquisa de iniciação Científica, nos infográficos em que a figura do corpo humano é evidente, acordes cromáticos artificiais podem agregar caráter inumano às imagens.

\subsection{Tamanho e disposição na página}

O segundo ponto diz respeito ao tamanho dos infográficos e à disposição na página. No caso dos infográficos publicados em livros didáticos, tanto naqueles que apresentam dados numéricos, através de mapas, quanto nos que demonstram o funcionamento de partes do corpo humano, o tamanho foi um dos problemas apontados pelos entrevistados. Segundo o professor Antunes, a ampliação do infográfico 'Recursos hídricos renováveis internos, por pessoa, por ano (2005) e projeção para 2050 - em metros cúbicos' (Figura 1)

16 Tufte, 2011a:67 
possibilitaria ao professor, entre tantas coisas, perguntar aos alunos questões mais específicas.

Para torná-lo mais que adequado, poderia ser em um tamanho ampliado, porque aí você conseguiria, por exemplo, perguntar coisas mais específicas. Como é um mapa-múndi e, lógico, um mapa muito ampliado você vai poder trabalhar para extrair mais informações. (Murillo Scaranari Antunes)

Ainda sobre o tamanho do infográfico e, também, a disposição na página, a professora Quinalha afirma:

Então, se ele fosse maior, ele poderia estar em destaque. Só ele. (...) Você vê que na mesma página, a gente tem aqui outro desenho, outra imagem. Então, na hora que o aluno está fazendo a leitura, ele vai olhar aqui, mas ao mesmo tempo ali... Porque a imagem chama a atenção. Então, eu acho que poderia ser só ele na página e maior. Ou ele e o texto, ou ele e outra informação. (Eliane Maria Rodrigues Quinalha)

O infográfico analisado está publicado na mesma página em que um infográfico sobre o aquecimento global apresenta ilustrações de animais, residências, indústrias etc. Para a professora Quinalha, isso é problemático, pois um infográfico como esse último "é muito mais agradável de se olhar" e atrai mais a atenção do aluno do que o infográfico selecionado, o que pode interferir no entendimento do tema, por parte do aluno. Ainda segundo a professora Quinalha, uma solução para o problema apresentado seria dar prosseguimento aos assuntos discutidos no texto e no infográfico selecionado, com informações sobre os aquíferos, por exemplo.

De modo geral, nos livros didáticos analisados, encontram-se infográficos comprimidos entre o texto principal e outras imagens. Os casos críticos envolvem infográficos que concentram um grande volume de informações e que deveriam estar impressos em escala maior, como ocorre em 'Recursos hídricos renováveis internos, por pessoa, por ano (2005)', em que é quase impossível distinguir as variações de tamanho do símbolo aplicado no infográfico, ou mesmo os países aos quais determinados dados se referem.

Outro problema apontado pela professora Quinalha se refere aos "dados não disponíveis" apresentados em cinza, que se referem, justamente, às áreas polares. Nesse caso, ao analisarem o infográfico, os alunos costumam questionar por que não há dados disponíveis, se é sabido que há água nos polos? Cabe, então, ao professor explicar que há, sim, água nos polos, mas está congelada.

A legenda tem que explicar o que você não entende olhando o mapa. E, para o professor, esse mapa é chato de analisar, então você imagina para o aluno... A legenda, ela tem isso, ela tem que explicar as cores e símbolos do mapa e não deixar dúvida. E o gráfico é o texto exibido de outra 
forma. (...) Então, eu acredito que, quando você vai elaborar um gráfico ou um mapa, você tem que pensar nisso: ele vai olhar e, através desses desenhos e cores, ele vai ter que entender o que eu quero. (Eliane Maria Rodrigues Quinalha)

Já em jornais e revistas, os infográficos premiados, que condensam muita informação ou exigem do leitor um olhar mais atento, são comumente impressos em dimensões maiores, às vezes, usando o recurso de página dupla, tripla ou, em casos especiais, papéis de maior escala, como em 'World of rivers' (Figura 2), o que garante a sua legibilidade. Como podemos observar no infográfico, as dimensões de 'World of rivers' possibilitaram a apresentação de informações sobre o assunto tratado, em textos organizados em blocos sobre as áreas no mapa que representam os oceanos.

\subsection{Combinação entre elementos gráfico-visuais}

Por fim, o terceiro ponto se refere à combinação entre os elementos gráfico-visuais nos infográficos. Em casos como 'Inclusão social no Brasil de acordo com o IDH' (Figura 5), que apresenta dados numéricos, professores apontaram a necessidade de associar o mapa apresentado no infográfico a outros tipos de gráficos, como os circulares ou em barra, por exemplo, que permitissem a comparação e análise percentual dos dados, de modo a auxiliar na discussão sobre o tema. O infográfico premiado 'Geografia do voto' (Figura 6) exemplifica esse tipo de solução ao combinar mapas do Brasil, mapamúndi, gráficos de barra e tabelas para apresentar os dados. E vai além, ao apresentar e comparar os dados sobre as eleições presidenciais brasileiras, através do recurso da constância de desenho, ou seja, da repetição do mapa do Brasil com variações de cor e tamanho, que criam uma hierarquia visual e possibilitam ao leitor explorar os dados fornecidos, através de associações e confrontos entre os mapas. A aplicação da constância de desenho enfatiza as mudanças de dados ${ }^{17}$, facilitando a visualização e a comparação também entre as estruturas, como foi possível observar no infográfico premiado 'As idades do sexo' (Figura 09). Nesse caso, a escala dos diagramas, representados em cinza, se mantém a mesma, o que varia é a aplicação da cor em pequenas áreas, que indicam a estrutura à qual o texto se refere. Para o professor Magalhães, o recurso de repetir a ilustração, ou a "constância de desenho", destacando em cor uma estrutura por vez, pode auxiliar e muito a compreensão da informação. Nas palavras de Tufte (2011a:65) "informação consiste em diferenças que fazem a diferença" 18 .

17 Ibidem.

18 Tradução livre 
No premiado 'The brain in slumber' (Figura 8), a solução, que poderia ser aproveitada para o uso nos infográficos didáticos analisados, foi a utilização do recurso do zoom, para ampliar detalhes da anatomia do cérebro e explicar o funcionamento de determinados processos. Esse tipo de recurso foi apontado pelos professores como uma solução também para casos complicados, como 'Recursos hídricos renováveis internos, por pessoa, por ano (2005)' (Figura 1), citado anteriormente, em que é difícil compreender em quais países os símbolos são aplicados, ou mesmo em 'Inclusão social no Brasil de acordo com o IDH' (Figura 5), de modo a possibilitar o estudo do IDH por áreas específicas do mapa apresentado.

\section{Considerações finais}

As análises das entrevistas com os professores possibilitaram compreender o quanto a relação entre a cor e os outros elementos do infográfico interfere no processo de transmissão da informação. E, também, como os infográficos premiados no Malofiej podem contribuir para o aprimoramento dos infográficos destinados aos livros didáticos. A cor incorpora significados às informações e, desse modo, o autor do infográfico tem total responsabilidade por suas escolhas, uma vez que, hoje, a complicada tarefa de antever os efeitos que a cor produzirá em determinada situação é atenuada com o auxílio do computador. Criar e manipular os elementos visuais, através de softwares, tornou possível comparar, alterar ou até mesmo descartar determinado elemento com poucos cliques do mouse.

Mais do que o aprimoramento dos infográficos publicados em livros didáticos, as análises das entrevistas e as duas iniciativas de projetos realizados com os alunos do Ensino Fundamental, que não foram abordadas neste artigo, apontaram para a importância de se proporcionar situações em que o aluno estabeleça "grande familiaridade com os elementos visuais" e, desse modo, se aproprie dos códigos visuais em seu processo de aprendizagem, ampliando sua cultura visual. Apesar de ser atraído pelas imagens, o olhar do aluno de Ciclo IV ainda não está treinado o suficiente para colher as informações oferecidas por elas de modo autônomo. É preciso um acompanhamento de perto, do professor, para que o infográfico seja explorado e as informações oferecidas por ele sejam aproveitadas no processo de ensino-aprendizagem. Segundo Donis A. Dondis,

Tudo isso faz do alfabetismo visual uma preocupação prática do educador. Maior inteligência visual significa compreensão mais fácil de todos os significados assumidos pelas formas visuais. (2007:231)

Para os professores entrevistados, diminuir a complexidade dos infográficos apresentados no livro não é a solução. Talvez, sim, acrescentar textos de apoio, outros tipos de gráficos e mapas, 
que auxiliem a discussão, mas nunca facilitar ou, nas palavras da professora Bianco, "mastigar" a informação. É preciso ampliar a cultura visual do aluno, proporcionar situações para que ele possa apropriar-se das imagens, em especial, dos infográficos, em seu processo de aprendizagem.

\section{Referências}

CANTO, E. L. (2009). Ciências naturais: aprendendo com o cotidiano (Volume 3). São Paulo: Moderna.

CANTO, E. L. (2009). Ciências naturais: aprendendo com o cotidiano (Volume 4). São Paulo: Moderna.

ERreA, J.; GIL, A. (Org.) (2011). 18 Premios internacionales de infografía Malofiej. SND-E. Madrid: Index Book.

ERreA, J.; GIL, A. (Org.) (2012). 19 Premios internacionales de infografía Malofiej. SND-E. Madrid: Index Book.

Errea, J. (Org.) (2013). 20 Premios internacionales de infografía Malofiej. SND-E. Madrid: Index Book.

DANELLI, S. C. S. (Org.) (2007). Projeto Araribá: geografia (Volume 3). São

Paulo: Moderna.

DANELLI, S. C. S. (Org.) (2007). Projeto Araribá: geografia (Volume 4). São Paulo: Moderna.

DONDIS, D. A. (2007). Sintaxe da linguagem visual. São Paulo: Martins Fontes. guimarães, L. (2003). A cor como informação. São Paulo: Annablume. Guimarães, L. (2004). As cores na mídia. São Paulo: Annablume.

HELlER, E. (2004). Psicologia del color: como actuan los colores sobre los sentimientos y la razon. Barcelona: Gustavo Gili.

Oliveira, M. C. C.; MIUCCI, C.; PAUla, A. (2009). História em Projetos (Volume 4): A encruzilhada dos mundos: consertos e desconsertos nos séculos XX e XXI. São Paulo: Ática.

Peltzer, G. (1991). Periodismo iconográfico. Madrid: Ediciones Rialp. TUFTE, E. R. (2011a). Envisioning information. Connecticut: Graphic Press. TUFTE, E. R. (2011b) The visual display of quantitative information. Connecticut: Graphic Press.

\section{Sobre os autores}

\section{Milena Quattrer,}

<mquattrer@gmail.com>

Graduada em Educação Artística - Artes Plásticas pela UNICAMP. Atualmente é aluna regular do curso de Mestrado em Artes Visuais (UNICAMP) e atua no grupo de pesquisa Design Criativo da Forma (UNICAMP). É Professora de Artes na Rede Municipal de Ensino de Campinas e Supervisora bolsista do Subprojeto de Artes Visuais PIBID/UNICAMP. 


\section{Anna Paula Silva Gouveia,}

<annagouveia@iar.unicamp.br>

Arquiteta e Doutora em Arquitetura e Urbanismo pela FAU USP. Diretora Associada do Instituto de Artes da UNICAMP. Professora nos cursos de graduação em Artes Visuais e Arquitetura e Urbanismo. Pesquisa os temas: metodologia de projeto e ensino, desenho, cor e tipografia aplicada à paisagem urbana, arte-joalheria.

Artigo recebido em 09 dez. 2013, aprovado em 28 dez. 2013. 